\title{
Commentary \\ Cardiovascular and metabolic responses to catecholamine and sepsis prognosis: a ubiquitous phenomenon?
}

Solène Collin, Nacira Sennoun and Bruno Levy

Equipe Avenir Inserm, Shock Research Group (Groupe Choc), Nancy Université, Faculté de Médecine, 54500 Vandoeuvre les Nancy, France

Corresponding author: Bruno Levy, b.levy@chu-nancy.fr

Published: 17 March 2008

This article is online at http://ccforum.com/content/12/2/118

(c) 2008 BioMed Central Ltd

See related research by Kumar et al., http://ccforum.com/content/12/2/R35
Critical Care 2008, 12:118 (doi:10.1186/cc6816)

\begin{abstract}
Many parameters have been associated with sepsis prognosis. In the present issue of Critical Care, Kumar and colleagues demonstrate that a preserved cardiac answer to dobutamine evaluated by radionucleotide measurements was associated with a better prognosis during septic shock. In this context, it is interesting to note that not only is the cardiac response to catecholamine stimulation associated with prognosis, but also the vascular and metabolic responses are associated. The ability of exogenous catecholamine to increase the arterial pressure (dopamine test) or to increase the lactate level is also related to prognosis. According to the ubiquitous character of catecholamine sensitivity, therefore, we should think in terms of cellular ability to respond to catecholamines in defining the concept of physiological reserve.
\end{abstract}

In the present issue of Critical Care, Kumar and colleagues [1] elegantly demonstrate using graded dobutamine challenge in septic shock patients combined with radionucleotide measurement of cardiac function that only the survivors were able to maintain cardiac responsiveness to dobutamine stimulation. In fact, the prognosis value of a positive response to dobutamine challenge has been already demonstrated in several studies, in which the answer to dobutamine was evaluated using different indices: the oxygen delivery/oxygen consumption relationship in Vallet and colleagues' study [2], or an increase in the cardiac index in the studies of Rhodes and colleagues [3] and of Jellema and colleagues [4].

It is interesting to note that not only is the cardiac response to catecholamine stimulation associated with the prognosis, but also the vascular and metabolic responses are associated. For example, it is well demonstrated that hemodynamic severity of septic shock is linked to the acuteness of vasoplegia. In animal models and human studies, vasoplegia is clearly related to hyporeactivity to exogenous and endogenous vasopressors (norepinephrine and vasopressin, for instance) [5]. Experimental and clinical data have demonstrated that, between the many factors involved, an overproduction of nitric oxide and peroxynitrite leading to the stimulation of vascular potassium channels is responsible for vascular hyporeactivity [6].

Despite this complicated pathophysiological network, it is possible to simply assess vascular reactivity and thus the septic shock prognosis using a dopamine test. We have previously demonstrated that dopamine-sensitive patients for example, patients who were able to increase their mean arterial pressure with a maximal dose of $20 \mu \mathrm{g} / \mathrm{kg} / \mathrm{min}$ dopamine - had a better prognosis (survival 78\%) when compared with dopamine-resistant patients (survival 16\%) [7].

At the least, the metabolic response can be evaluated by the ability to produce lactate. During septic shock, lactate production may be related not only to a hypoxic mechanism but also to an increased metabolic demand. Experimental data have demonstrated that lactate production in the muscle is linked to epinephrine stimulation of the $\mathrm{Na}^{+}, \mathrm{K}^{+}$-ATPase pump. In human septic shock, we also demonstrated that muscle was a net producer of lactate, and that this production could be totally inhibited by ouabain, thus confirming a $\mathrm{Na}^{+}, \mathrm{K}^{+}$-ATPase-dependent mechanism while clearly independent of tissue hypoxia [8]. Muscle tissue, which represents approximately $40 \%$ of the total body cell mass, is particularly implicated in this mechanism, notwithstanding that $>99 \%$ of muscle adrenergic receptors are $\beta_{2}$ receptors.

We recently demonstrated in low-flow (hemorrhagic) and normal-to-high-flow models of shock (endotoxin and peritonitis) that lactate production during shock states is related, at least in part, to increased $\mathrm{Na}^{+}, \mathrm{K}^{+}$-ATPase activity under $\beta_{2}$ stimulation [9]. Levraut and colleagues, using an infusion of exogenous lactate to estimate lactate production and clearance, found in stable normolactatemic septic shock patients that survivors produced more lactate than 
nonsurvivors [10]. Similarly, the survivors were also better able to clear this overproduction of lactate.

The response to catecholamine can therefore be studied at the heart level using $\beta_{1}$ stimulation, at the vessel level using $\alpha$ stimulation, and at the metabolic level using $\beta_{2}$ stimulation. It remains unknown, however, whether this disturbed answer to catecholamine response is due to a signaling problem at the receptor or postreceptor levels or due to the tissue's inability to produce the physiological answer, or both.

To conclude, according to the ubiquitous character of catecholamine sensitivity, we should think in terms of cellular ability to respond to catecholamines in defining the concept of physiological reserve rather than in terms of preload or cardiac reserve.

\section{Competing interests}

The authors declare that they have no competing interests.

\section{References}

1. Kumar A, Schupp E, Bubbel E, Ali A, Milcarek B, Parillo JE: Cardiovascular response to dobutamine predicts outcome in severe sepsis and septic shock. Crit Care 2008, 12:R35.

2. Vallet B, Chopin C, Curtis SE, Dupuis BA, Fourrier F, Mehdaoui H, LeRoy B, Rime A, Santre C, Herbecq P, et al.: Prognostic value of the dobutamine test in patients with sepsis syndrome and normal lactate values: a prospective, multicenter study. Crit Care Med 1993, 21:1868-1875.

3. Rhodes A, Lamb FJ, Malagon I, Newman PJ, Grounds RM, Bennett ED: A prospective study of the use of a dobutamine stress test to identify outcome in patients with sepsis, severe sepsis, or septic shock. Crit Care Med 1999, 27:2361-2366.

4. Jellema WT, Groeneveld AB, Wesseling KH, Thijs LG, Westerhof $\mathrm{N}$, van Lieshout JJ: Heterogeneity and prediction of hemodynamic responses to dobutamine in patients with septic shock. Crit Care Med 2006, 34:2392-2398.

5. Landry DW, Oliver JA: The pathogenesis of vasodilatory shock. N Engl J Med 2001, 345:588-595.

6. Pacher P, Beckman JS, Liaudet L: Nitric oxide and peroxynitrite in health and disease. Physiol Rev 2007, 87:315-424.

7. Levy B, Dusang B, Annane D, Gibot S, Bollaert PE: Cardiovascular response to dopamine and early prediction of outcome in septic shock: a prospective multiple-center study. Crit Care Med 2005, 33:2172-2177.

8. Levy B, Gibot S, Franck P, Cravoisy A, Bollaert PE: Relation between muscle $\mathrm{Na}^{+} \mathrm{K}^{+}$-ATPase activity and raised lactate concentrations in septic shock: a prospective study. Lancet 2005, 365:871-875.

9. Levy B, Desebbe O, Montemont C, Gibot S: Increased aerobic glycolysis through beta-2 stimulation is a common mechanism involved in lactate formation during shock states. Shock 2008 [Epub ahead of print].

10. Levraut J, Ichai C, Petit I, Ciebiera JP, Perus O, Grimaud D: Low exogenous lactate clearance as an early predictor of mortality in normolactatemic critically ill septic patients. Crit Care Med 2003, 31:705-710. 